\title{
WOMEN AND INFORMATICS: THE AdA Web PORTAL
}

\author{
Emanuela Boschetto \\ Dipartimento di Informatica \\ Università Ca' Foscari di Venezia \\ Italy \\ boschetto.e@hyphen-italia.com
}

\author{
Agostino Cortesi \\ Dipartimento di Informatica \\ Università Ca' Foscari di Venezia \\ Italy \\ cortesi@unive.it
}

\begin{abstract}
The gender gap in Informatics education is becoming a crucial issue. Over the last four years, the number of women enrolled in IT-related bachelor programs in Italian universities has dramatically decreased, by around $30 \%$. Today, only 15\% of Informatics students are female, while the overall percentage of females enrolled at Italian universities is more than 55\%. The aim of the Ada Web Portal we present in this paper is to facilitate communication and to share experiences between women (students, teachers, and professionals) working in the IT area.
\end{abstract}

\section{Keywords}

Gender Gap and IT, Online Resources and Instruments, Women and Computer Science.

\section{INTRODUCTION}

The gender issue in Computer Science is a worldwide problem. Not only do men still largely outnumber women in IT education, but during the last few years the gender gap has dramatically increased. There are many actions and projects promoting women's access to IT, in particular from an educational perspective. For example, significant research papers have been produced from researches and surveys (see references [1] and [2]), and there have been meetings focussing specifically on this topic (see reference [3] for instance).

How can we promote women in Computer Science? The starting points, in our opinion, are (1) to emphasize the crucial role played in the history of Informatics by female scientists; (2) to stress the multidisciplinary challenges of IT, which require a variety of attitudes and may very well benefit from gender differences both in problem solving and in technology design, and (3) to share living and working experiences among women in Computer Science, in order to create a spirit of community.

This is not an easy task, and it requires the contribution of various players (universities, industries, professional associations) in order to amplify the message of the very positive impact on society of having a greater number of women as actors of the future technologies. Measures are needed to increase women's participation and leadership in the innovative field of Informatics, beginning with the early encouragement of girls, and continuing through to the creation of women-welcoming environments in Engineering and Information Technology.

The Ada Web Portal we present in this paper (http://www.dsi.unive.it/ADA) can be seen as a tiny contribution to addressing the gender issue. It is part of a larger project called "ADA - Promoting Women's Access to Computer Science", promoted by 34 Computer Science departments in Italy, in partnerships with prominent industrial associations such as Assolombarda and Confindustria Veneto. The project aims at implementing a suite of actions to enhance women's participation in IT, and to create job opportunities that fit with the domestic aspects of women's lives. The project targets female students in high schools, in particular those in the final two years. Teachers are also involved, as actors designing guidelines and tools for educational orienteering. The team members manage activities for the project locally. In this way, the Ada Project is spreading action throughout Italy.

In what follows, we first depict the Italian scenario (although most of the figures also fit an international perspective), and then present the architectural design of the ADA website.

\section{Women AND COMPUTER SCIENCE IN ITALY}

The Ada Web Portal originated from some analytical studies of the IT gender gap in Italy. The researchers focussed on women and Information Technology at various levels, exploring the different paradigms of accessing technology. This included studies of women attending university courses, performing academic research and teaching, as well as studies of women working in the IT industry. The findings of this research represent the raw material for the creation of the ADA Web Portal. 
In Italy, fewer women are enrolling in Computer Science courses. Furthermore, there are very few women operating as IT researchers, professors, or IT professionals. Below, we report some data for the Italian situation regarding these three categories.

\subsection{Women as Students}

The number of female students enrolled in Informatics bachelor courses in Italy has steadily declined, from 1,059 in 2003/2004, to 756 in 2007/2008. Over the last four years, there has been a remarkable difference between the numbers of men and women enrolling in Informatics:

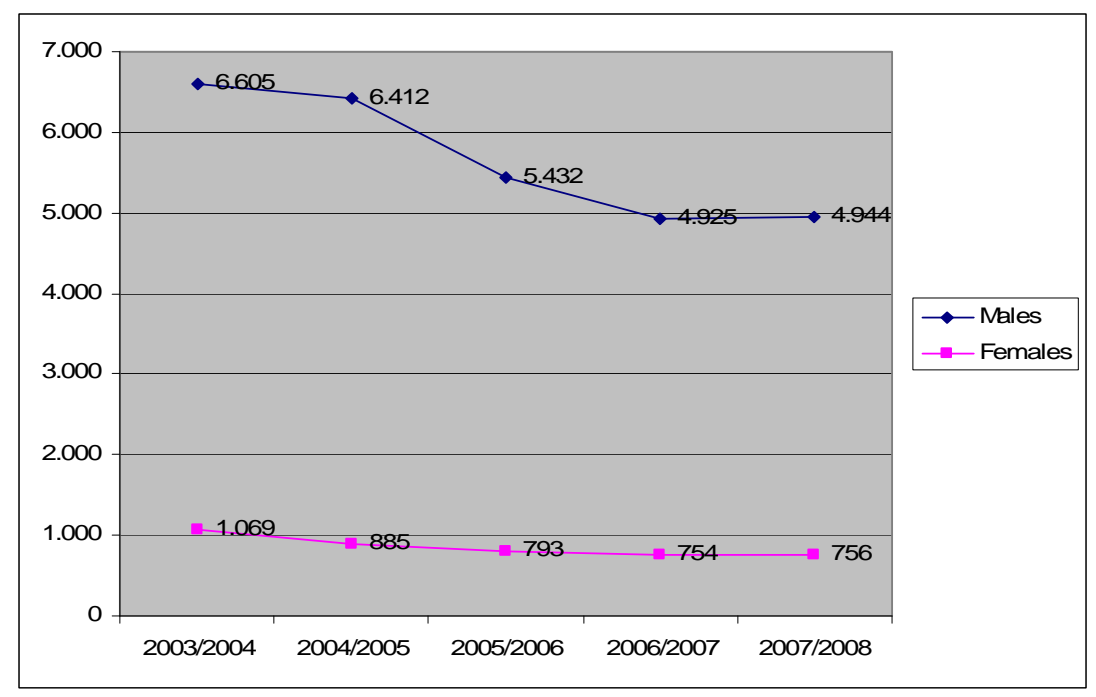

Figure 1a Comparison between men and women enrolling in Computer Science the last four years in Italy [4]

It is also interesting to compare the data above with data from other countries: Figure $1 \mathrm{~b}$ depicts the gender distribution of new CS students pursuing bachelor, master, or diploma studies at ETH Zurich, Switzerland.

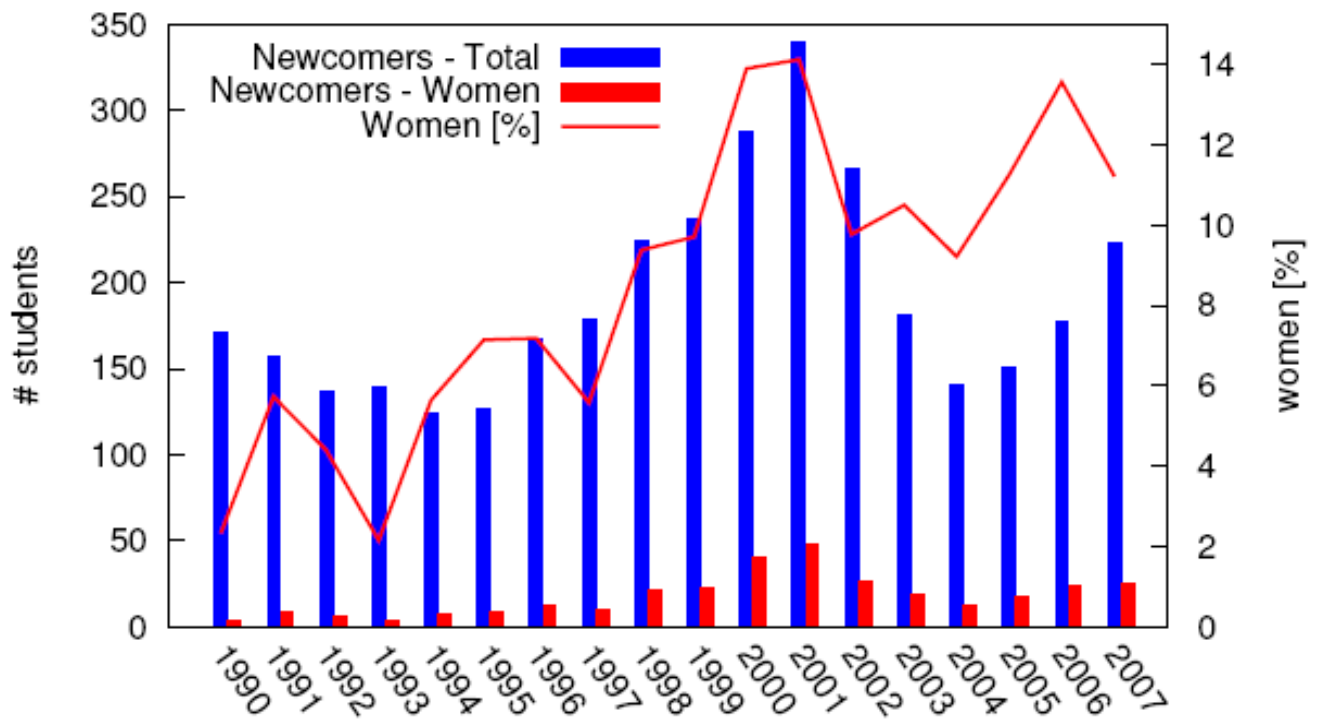

Figure 1b Comparison between men and women enrolling in Computer Science at ETH-Zurich [3]

A selected sample of the Italian university system data reveals that female students account for only $15.2 \%$ of the IT student body; while overall, women represent $55.6 \%$ of students in Italian universities (Figure 2). 


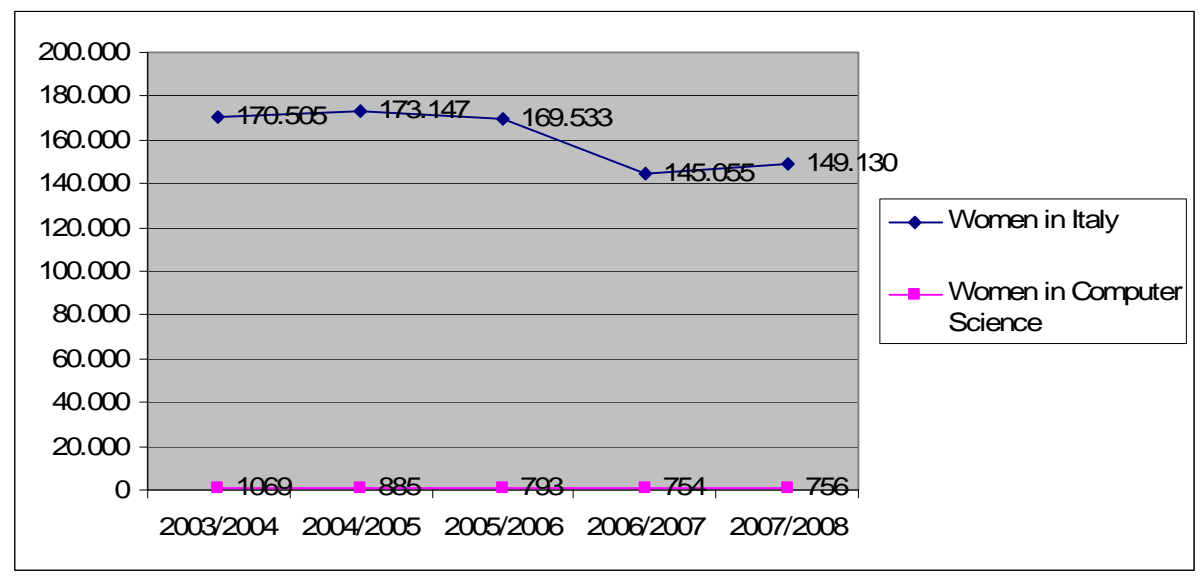

Figure 2: Comparison between female students in Italian universities and female students enrolled in Informatics study programs [4].

\subsection{Women as Researchers}

The percentage of women in IT academic research and education in Italy remained almost unchanged from $2000(26 \%)$ to $2008(27.7 \%)$. The slight growth of $1.7 \%$ took place during the final two years of that period (Figure 3).

During the same period the teaching body of Computer Science increased from 483 to 811 teachers nationwide. The number of women is higher at the lowest levels of the academic hierarchy, in the roles of researcher or associate professor, rather than full professor. In 2008 female professors represented $6.1 \%$ of the overall academic teaching staff (compared to male professors at 22.4\%), while female researchers represented 11.2\% (Figures 4 and 5).

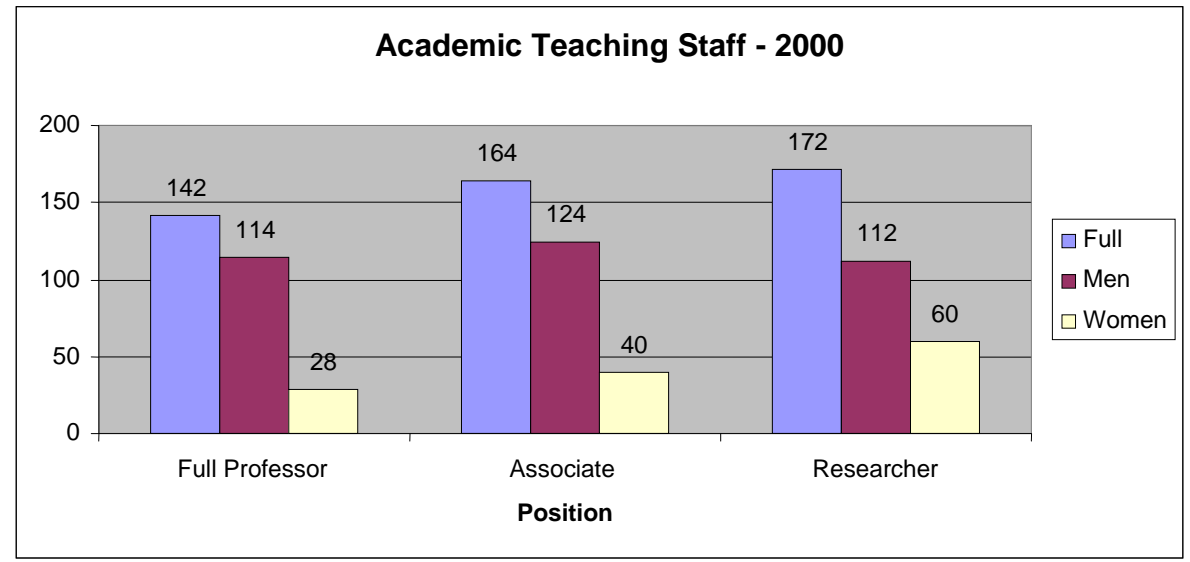

Figure 3: Academic Teaching Staff and Roles in 2000 [4]

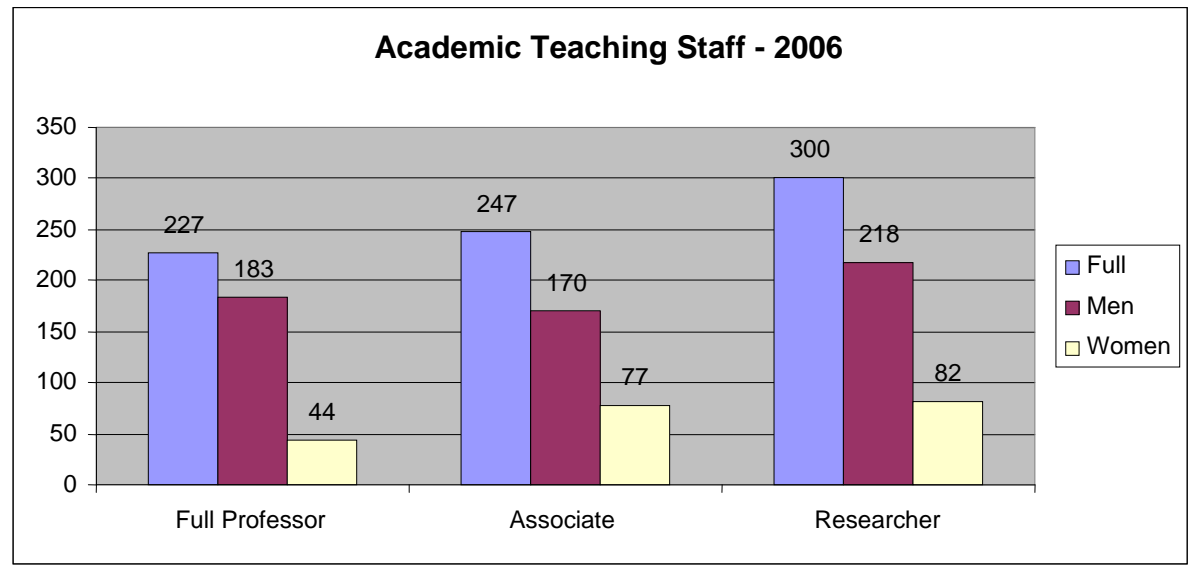

Figure 4: Academic Teaching Staff and Evolution of Roles in 2006 [4] 


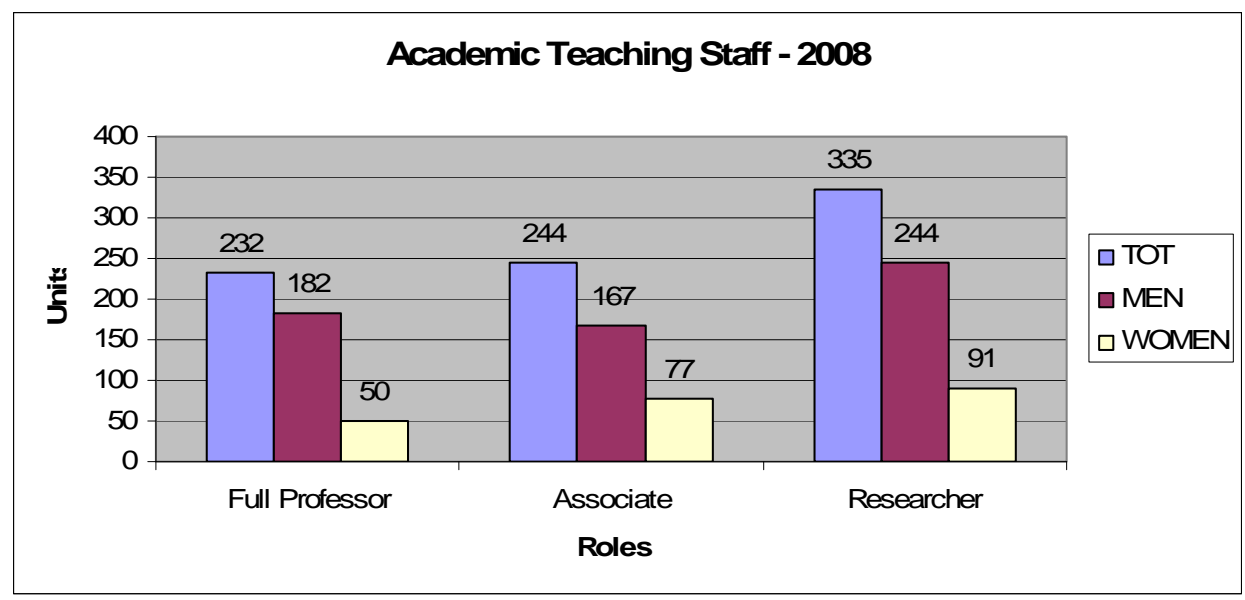

Figure 5: Academic Teaching Staff and Evolution of Roles in 2008 [4]

\subsection{Women as IT Professionals}

The under representation of women in the Italian labour market as a whole is well-known. In 2006 the employment rate for Italian women was $46.6 \%$, one of the lowest in Europe. In the IT sectors too, women professionals are still a minority group. In 2004 , among a total of around 670,000 IT professionals in Italy, only $14 \%$ were female.

In recent years there has been a slight increase in the overall number of employees in the IT industry in the EU-27 [5]. In 2004, 19\% of people employed in the IT area in Europe were women (EU-27). Female professionals are more and more present at the decision-making level in major ICT companies, but are still under-represented. An analysis made in October 2007 of 150 European telecommunications companies found that on average, women accounted for $6 \%$ of individuals on boards of directors. This is clear evidence that there is still much work to be done to attract women to take up a career, and then remain, in the ICT sector [6].

Despite the predominance of male professionals, recent research papers and statistics offer surprising data:

1. Between 1997 and 2001 the number of women in IT professions in Italy exceeded the European average of women workers in IT (see Table 1).

\begin{tabular}{|ccccccc|}
\hline & & 1997 & & & \multicolumn{2}{c|}{2001} \\
Italy & 39.4 & 82.1 & 32 & women & men & \% women \\
UE 15 & 279.9 & 727.1 & 28 & 67.3 & 135.5 & 33 \\
\hline
\end{tabular}

Table 1. Men's and women's employment, European labour market in IT sectors (in thousands) [7]

2. In Italy, in the years 2004 to 2006 , the percentage of women professionals in IT grew by $2.5 \%$ (from $14 \%$ to $16.5 \%)$, following the EU-27 trends.

3. Women's technological skills are superior to men's. Women give more importance to their technological training, as shown by Table 2 below.

\begin{tabular}{|ccc|}
\hline & Women & Men \\
Power User & $30.3 \%$ & $25 \%$ \\
No User & $26.2 \%$ & $27.6 \%$ \\
\hline
\end{tabular}

Table 2. Comparison between male and female use of IT in Italy [8] 
4. A recent research run by Towers Perrin among 15 of the main tech companies in the EU, Middle East and Africa, found that in Italy in $2004,24 \%$ of all employees were women. Italy was among the countries which had more women in technical roles, at the same level of Sweden and only surpassed by Denmark (23\%) and Ireland (26\%) [9].

The percentage of women acting as IT power users is significantly higher than men, though it is widely agreed that women have traditionally been much less likely than men to participate in Computer Science, Technology and Engineering subjects in schools and colleges.

The reason why there are so many women IT professionals might be found in the peculiar features of the new job categories related to IT. Women are attracted by the dynamism and flexibility granted by IT professions, which are structured in:

- Teamwork

- Working on projects

- Working with customers

- Networking and web communities

Women working in the IT sectors know that they are accessing a new field in which they can find new opportunities for better integration between the professional and the domestic sides of life. They also know that this is a chance to access a world where people must display and use their own know-how, which is the real value of a worker.

\section{The Ada Web Portal}

The Ada Web Portal (see Figure 6) has been developed to facilitate communication and sharing of experience among female students, teachers and professionals working in IT, both in academia and in industry. It serves as a "bridge" between high schools, colleges and the workplace, addressing the needs of different roles in the world of Women and Computer Science. It extends beyond the specific target of female students and reaches out to female teachers and professors, researchers and women who play key roles in IT Research and Development. It is a tool for young female students who are approaching university, helping and guiding them in their decision-making for their future careers. It also provides a collection of resources, articles and documents useful to teachers and women who work in IT. Therefore, the Ada Web Portal becomes an information resource and a channel for discussion among young female students, teachers and IT professionals. Among the tools used to promote interaction and communication between these various players are a forum, a newsletter, and FAQ.

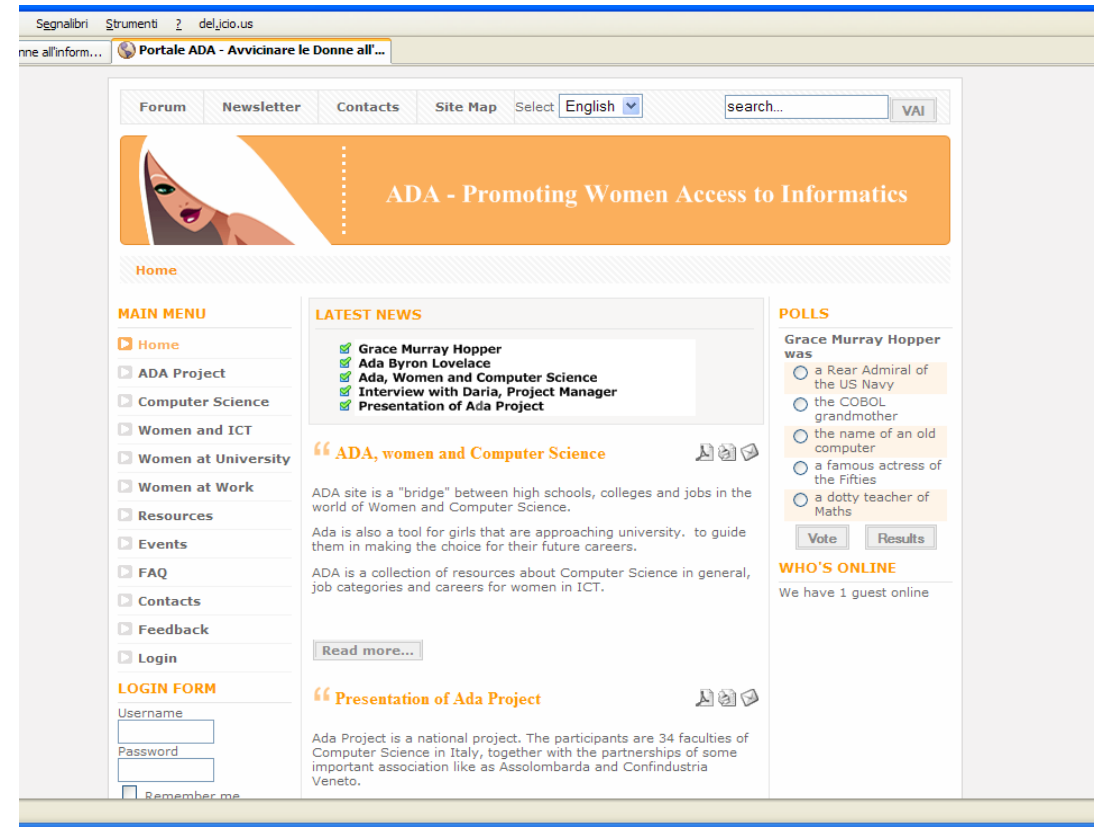

Figure 6: The Home Page of the Ada Web Portal (http://www.dsi.unive.it/ADA) 
The site promotes the sharing of experiences and best practices, providing role models for female students and encouraging them to access IT courses and careers. Women have contributed to the evolution of Computer Science in many different ways, and through the Ada Web Portal we want to acknowledge their key role. In fact, the first "computer leaders" were women. Ada Byron Lovelace was the first programmer; Grace Murray Hopper created the COBOL language; and during World War Two six brilliant women programmed the Eniac, the first large-scale, electronic, digital computer. Their stories are crucial as inspiration for all those girls and women who wish to access the field of Computer Science with more self-confidence.

In addition to this series of historical profiles of female pioneers in Computer Science, the Ada Web Portal offers interviews with women who majored in this area and are now working as project managers, programmers, product specialists or software analysts in IT. The Portal is intended to introduce a new perspective on Computer Science, investigating it from the point of view of all those women who are contributing every day to the evolution of the field. Ada is also a tool to keep track of official documents, articles, interviews and findings of all the researches made within the more general ADA Project.

\subsection{Navigation Hierarchy}

The Ada Web Portal is not just a repository: it has been designed as a working space, open to multiple contributions, in a typical Web 2.0 approach. It is structured in three main navigation levels. Figure 6 displays the site map and the navigation structure of the Web Portal.

The public areas of the Portal are divided into eight main sections, while there is also a restricted area for registered users.

The main content part is divided into two categories:

- Documentary and informative contents

- Interactive contents

\subsection{Key Features of the ADA Web Portal}

To our knowledge there are no other web portals covering the subject of Women in Computer Science, providing both a wide-spectrum collection of information and a discussion and interaction plaza. The main features of the portal are divided into static and interactive contents (see Figure 7).

The main static components of the Ada Web Portal are:

- An historic research section, with a collection of historical profiles of the first female IT pioneers;

- Two sections dedicated to statistics and reviews of demographic data regarding women in Italian universities, in the roles of both students and researchers;

- Success stories: interviews with female professionals. In this section, women tell their stories, talking about their past experience at university, and their present occupation in the field. These stories provide a meaningful medium to encourage young females to choose Computer Science as a career;

- An overview of Computer Science degrees in Italy, providing guidance to students on how to choose the most suitable faculty, based on their requirements and expectations.

The interactive part of the Web Portal includes:

- A Resources section, providing a selection of links to national and international projects promoting women's access to Computer Science; and an anthology of articles, documents and conference proceedings regarding Gender Gap and Gender Issues in IT.

- An Events section, which provides information about conferences, important academic events and meetings related to women in Computer Sciences.

- A large section of interactive content, including Forum, FAQ, Newsletter, Posted Questions and Answers, and a space where young women can interact and communicate with experts.

- The website has been designed to create an appealing environment for high school students, in order to encourage them to interact through it. 


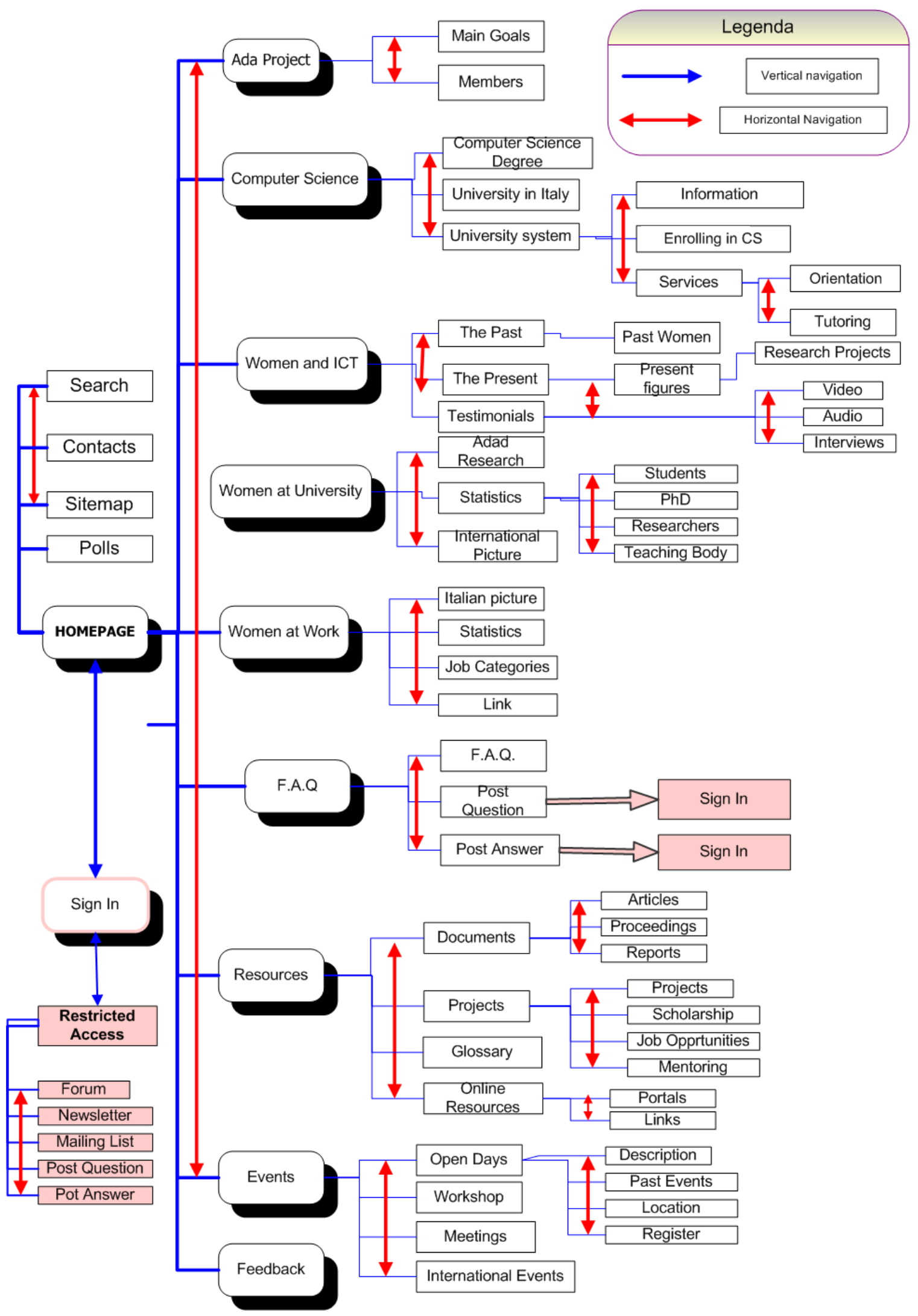

Figure 7: Ada Portal structure and navigation hierarchy 


\section{Other Projects (WorldWide Resources)}

The Ada Web Portal was developed after a detailed analysis on other similar projects worldwide. The most relevant are Computergirl.us, Technedonne Portal and Women@SCS.

\subsection{Computergirl (http://www.computergirl.us)}

Computergirl is a website originally created by a team of female high school students. It has since become an Association for Computing Machinery's Committee on Women in Computing (ACM-W) project.

The Computergirl mission is to: "encourage high school girls' interest in Computer Science; address questions and concerns; provide a window from experts and role models to students; share resources".

Computergirl inspired our selection of resources for the Ada Web Portal. It also showed us the relevance of collecting interviews with testimonials, in order to build up a gallery of role models for young women accessing Computer Science.

\subsection{Technèdonne (http://www.technedonne.it)}

TechnèDonne is a project financed by the EU "Equal" Program. It aims at fighting the professional segregation of women in the field of the new information technologies, and seeks innovative strategies to cope with the gender digital divide. The project uses a website to offer the necessary resources to grant equal opportunities to women and men in the field of IT, trying at the same time to remove obstacles that are socially constructed.

The Technèdonne website provides a large number of articles, documents, research papers and other resources about the relationship between women and new technologies. It has been a rich source of information for the Ada Web Portal. Thanks to Technèdonne, we have learned that women and girls have to get involved in concrete initiatives to reach self-confidence in the use of IT. We can use their experiences to organize Ada Project initiatives with more awareness of the real needs of women in this field.

\subsection{Women@SCS (http://women.cs.cmu.edu/)}

Women@SCS, founded in 1999, is a community of women attending the School of Computer Science (SCS) at Carnegie Mellon University, Pittsburgh (USA). Its mission is to create, encourage, and support academic, social, and professional opportunities for women in Computer Science, as well as promoting the breadth of the field and its diverse community.

The project's Advisory Committee consists of undergraduate students, graduate students, and faculty within the SCS. The Committee has initiated many programs, such as the Big/Little Sister program for undergraduates, the Invited Speaker Series for graduates, as well as dinners and other social and academic events. Women@SCS also sponsors outreach projects such as the "Is there a robot in your future?" workshop for middle school girls, and the Women@SCS Outreach Roadshow, with its different versions for undergraduates, schoolchildren, teachers, and parents.

Today the Committee remains active, providing help to new entrants to Computer Science and promoting a healthy and supportive community atmosphere. The analysis on the activities of Women@SCS represents a practical guide for building a student organization within the Ada Project and designing activities and events that can encourage and support a community of women in Computer Science.

\subsection{Informatica Feminale}

The project "Informatica Feminale - Summer University for Women in Informatics" was started in May 1997 in the Department of Informatics at the University of Bremen (Germany), and continues as an established part of that Department. Three aspects are seen as focal points: new definitions of Informatics curricula from women's viewpoints; creation of test-fields for new educational concepts, mainly in the context of summer courses, and further education for female university staff in Informatics. The intention is to bring together female students and scientists from all German higher education Informatics Departments, alongside women IT professionals. More information can be found at http://www.netzwerk-fit.de/informatica/.

\subsection{Other CS-Groups}

A list of groups relating to women in Computer Science/Computing can be found at http://cs-www.cs.yale.edu/homes/tap/cs-women-groups.html.

\section{Conclusions}

This concluding section addresses three fundamental questions:

1. How are female students motivated to visit the Portal and to engage in its various activities? 
2. What have been the impact and the results of the ADA Portal so far?

3. How will its future impact be measured?

The students will be motivated to visit the Ada Portal and to engage in its various activities through a series of actions, comprising:

- Promotional actions using e-mail and newsletter campaigns directed to high school teachers. The teachers targeted are those involved in multimedia projects such as the creation of the school website. We provide information about the Ada Portal, and request their feedback and opinions. We also encourage them to provide links to the Ada Portal in their website link sections;

- Reviews of and nationwide dissemination of information about the Ada Portal through a network of websites covering women and new technology;

- Links to the Ada Web Portal from a number of university websites, cooperating with University Ca' Foscari of Venice;

- Organization of events and meetings, including a Ca' Foscari Faculty of Computer Science presentation to high schools, as well as a series of Open House days with practical sessions.

To date, the ADA Portal promotion and media information activities have yielded the following results:

- Some partnerships with high schools have already been established in order to put into action orientation activities with female students.

- Since its opening, the Ada Portal has had an average of 20 visitors a day. It is worth nothing that half of the users reach the Ada Web Portal using web search tools.

- Several university students have expressed their interest in the website and its contents. They have asked for our help in order to get more documentation about the history of women in Information Technology. Graduate students in Computer Science at the University of Naples Federico II have quoted resources from the Ada Web Portal in their dissertations.

- An interview on the activities of the Ada Project and the Portal have been published online at http://www.dols.net, an Italian website on women and new technologies.

- The Ada Web Portal was quoted by II Sole 24 Ore, a respected Italian newspaper with national circulation, in the article: "Women and ICT: the right match" (12/11/2007).

The impact (or relevance) of the ADA Web Portal on the Italian IT community will be monitored through the following means: web statistics; upgrading of the research section with annual data on the participation of women in IT; analysis and registration of the most significant forum topics, and registration of keywords used with search engines to retrieve the website.

\section{REFERENCES}

[1] A Study on the Status of Women Faculty in Science at MIT, The MIT Faculty Newsletter, XI (4), March, (1999), http://web.mit.edu/fnl/women/Fnlwomen.htm [Accessed 16/06/09].

[2] ALMALAUREA, http://www.almalaurea.it [Accessed 16/06/09].

[3] Proceedings of the 5th European Symposium on Gender \& ICT - Digital Cultures: Participation Empowerment - Diversity, March 5-7, (2009), University of Bremen, http://www.informatik.unibremen.de/soteg/gict2009/page/proceedings.html . [Accessed 16/06/09].

[4] MIUR, http://www.miur.it [Accessed 16/06/09].

[5] ISTAT, Rilevazione sulle forze di lavoro - IV trimestre, (2007), http://www.istat.it/salastampa/comunicati/in calendario/forzelav/20080320 00/ [Accessed 16/06/09].

[6] Press Release, European Commission, Women Wanted in Europe's ICT Industry, 6 March, (2008), http://europa.eu/rapid/pressReleasesAction.do?reference=IP/08/392 [Accessed 16/06/09].

[7] EUROSTAT, Statistics in focus, Employment and earnings in high-tech sectors, Nr.32/2007.

[8] FEDERCOMIN, ICT Professions and Employment, B\&C Editoria e Stampa Srl, Roma, (2006).

[9] A summary of the unpublished research run by Towers Perrin for Microsoft is in http://www.universitadelledonne.it/condorelli.htm [Accessed 16/06/09]. 